\title{
Wear evaluation study of the multiple grooved pulleys with optical method
}

\author{
Piotr Krawiec ${ }^{1, *}$, tukasz Warguła ${ }^{1}$, Konrad Waluś $^{1}$ and Jaroław Adamiec ${ }^{1}$ \\ ${ }^{1}$ Poznań University of Technology, Chair of Basics of Machine Design, Piotrowo 3 60-965 Poznań, \\ Poland
}

\begin{abstract}
Multiple grooved pulley wear can be evaluated by using two methods, coordinate method and optical method. This paper presents the results of the research and the analysis of the geometrical features for this type of pulleys, which was obtained with the ATOS II optical system. In this method the evaluation of wear is made based on the comparison of the manufactured parts or assemblies with superimposing the CAD model and the surface model obtained from digitization. Existing differences can be easily determined by their visualization in the form of a colored map of deviations or profile differences. This method is subject to a methodological error, which is a result of the accuracy of the scan and the correctness of the model's fit. Optical techniques can be used to determine the accuracy of the geometric features for products made with any shaping technique (machining, plastic processing, incremental methods, etc.).
\end{abstract}

Keywords: v-belt, multi-groove belt, optical measurements, pulleys wear

\section{Introduction}

The history of using tie-rods in machines and mechanisms goes as far as the bronze age (2100-950) B.C [1] One of the first known application of tie-rods was the construction of the universal machine (Fig. 1a). It was a starting point to construct in the country of Egypt many machines such as primitive turning lathe (Fig. 1b).

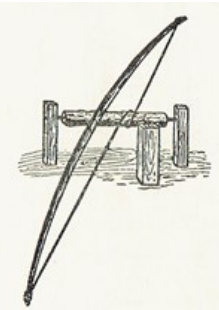

Fig. 1a. Reconstruction of Universal machine [1]

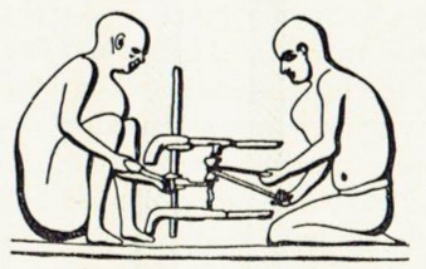

Fig. 1b. On the left a Turner with a knife, on the right a helper moving a spindle with a leather band [1]

\footnotetext{
*Corresponding author: piotr.krawiec@put.poznan.pl

Reviewers: Marek Macko, Alžbeta Sapietová
} 
Leonardo da Vinci on the other hand suggested using ropes (belts) to transmit loads between active and passive shafts (Fig. 2).

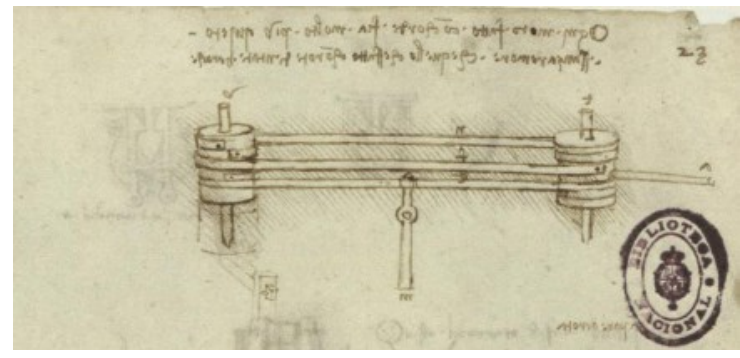

Fig. 2. Transmission belt designed by Leonardo da Vinci [1]

Common application of transmission belts dates back at the turn of $19^{\text {th }}$ and $20^{\text {th }}$ century. Then a few companies were founded that specialize in supplying and applying of flat, V-belts, toothed and round belts.

Since the very beginning of applying different kinds of belts and pulleys a research has started in order to both increase the range of transmitted loads as well to uprate their durability and wear resistance [2-7].

The assessment of geometrical features of belt and V-belt pulleys can be carried out with the use of three methods. The first method uses classis measurement tools (a set of rollers, depth caliper, protractor). Second method uses a coordinate measurement machine [8-10]. The third one is the use of optical system. This article presents research and analysis results of geometrical features of such pulleys with the use of optical device ATOS II. The optical method is relied upon the comparison of produced parts or systems by putting CAD model on a surface model obtained thanks to digitalization. The existing differences can be easily determined by visualising them in a form of a colourful map of deflections of profile differences. This method however, is burdened with methodological mistake resulting both from scanning precision and the correctness of matching the models. The optical method can be used to determine the preciseness of imitating the geometrical features of products manufactured by any shaping technology (machine cutting, plastic forming of metals, additive methods, etc.).

\section{The wear of V-belt pulleys}

Belt and V-belt pulleys have a wide application in the production of means of transport. In cars belt transmissions are used i.e. alternator drive, steering wheel assistance or air conditioning compressor. The increase of the working parameters of a passenger vehicles (speed, torque) increases the level of vibrations and noise from transmission. A natural solution of this problem becomes applying in car constructions both transmissions and dampers whose working principle and construction would limit these negative phenomena. The causes of improper work of a belt or V-belt transmission can be as follow: assembly of a new pulley with the use of old or improper bolts or assembly mistakes i.e. using a wrong torque while tightening the bolts. It is very vital to ensure a proper assembly of the pulley.

Proper selection of the material of which the multigrooved belt pulleys are made, is one of the main features which have an influence on the pulley wear and belt transmission life. In order to reduce the mass of the pulley, it is reasonable to consider aluminum alloys as its material. The valuable analysis of these materials connected with testing its various strength properties, was presented in following papers [11-13]. 
In order to make the assembly process more effective and to ensure high precision of positioning it is advisable to use special tools. An interesting solution is a device SKF TKBA 40 that is used to position pulleys to belts in the belts'grooves. Its wedge guides and strong magnets enable a quick and easy assembly into the pulley's grooves. The device consists of two main parts; first one emitting a laser ray and a second one which is a receiver. This device allows to assembly the pulley in a quick and reliable way.

The symptoms of wear of V-belt pulleys are:

- loud work of V-belt,

- sliding off of the V-belt,

- rust on the outer side of the wheel,

- the increased level of vibrations,

- deformation of pulley's groove as well as cracks,

- parts of the belts are worn.

In order to ensure a proper level of pulleys' reliability it is necessary to apply verified measurement methods.

\section{Classic geometrical values measurement procedure for belt and V-belt pulleys}

The issues of the measurements of geometrical and exploitation features of belt transmissions are still valid and important. In literature [14] it is possible to find the research results for transmissions with belt and toothed-belt.

Classis measurement procedure consists of three tasks: first one is the measurement of the divisional diameter of the pulley, second to check the coaxialness of the divisional diameters, the third one is to check the value of the angle of the groove outline.

The measurement of the divisional diameter of the pulley is carried out similarly as in case toothed pulleys with the use of measurement rollers of a $d_{p}$ diameter. In order to determine and actual diameter of the pulley first $K$ dimension is measured and then in accordance with the equation (1) divisional diameter $\mathrm{d}$ is determined

$$
d_{p}=K-2 x_{p}
$$

Picture showing this task is presented in Figure 3.

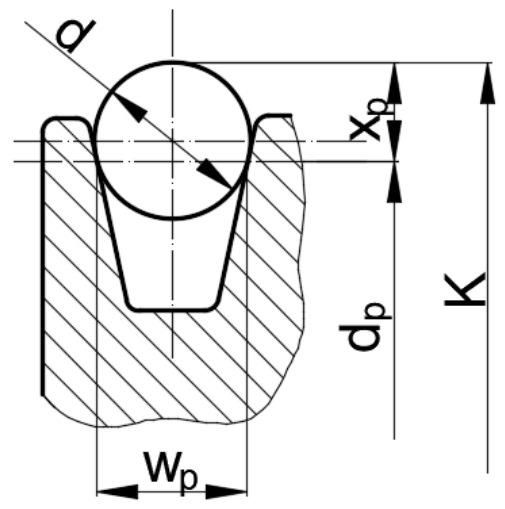

Fig. 3. The measurement of the divisional diameter of the pulley with the use of the rollers

Checking the coaxialness of the divisional diameters is performed with the use of depth caliper. The dimension $b$ is measured directly in the entire circumference of every groove of the pulley. The measurement method is presented in Figure 4. 


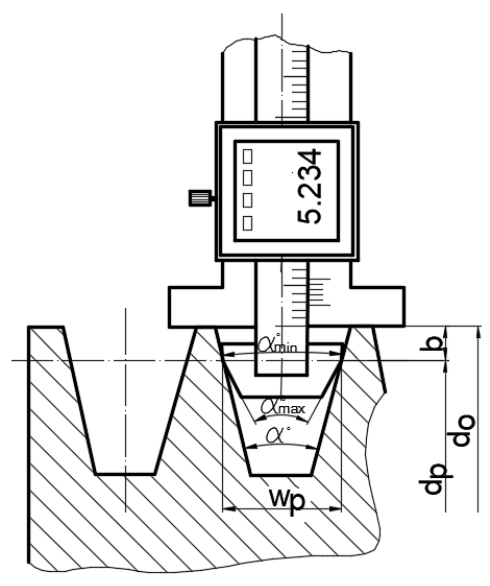

Fig. 4. Depth caliper used for the measurement of $b$ dimension of the pulley

Checking the value of the angle of the groove outline is carried out by performing the difference test. Measurement procedure is shown in Figure 5.
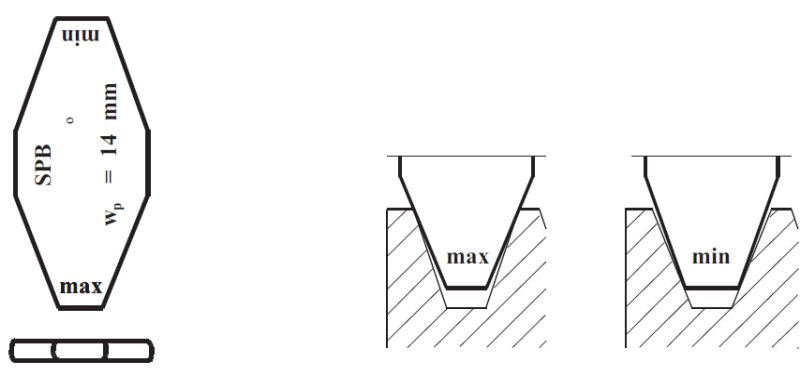

Fig. 5. The test of the angle of the pulley groove outline

In order to determine the dimensions of groove pulleys for compound belts with a narrow profile the following ISO 5290 standards are applied whereas for compound belts with a standard profile ISO 5291 respectively .

International standards ISO set the effective (upper) nominal width of the pulley's groove as a base value for the normalization of the pulley's groove and matching compound belts. The effective width of the groove means the biggest dimension of the grove measured on its rectilinear sides. For all measurement pulleys and mostly for machinery pulleys produced in series this assumption equals to the actual upper width of the groove. The position of the divisional diameter $d$ (effective one) in that case can only be treated as an approximate value. In order to calculate the dimensions and the power of a transmission the effective (external) diameter of the pulley is used. 


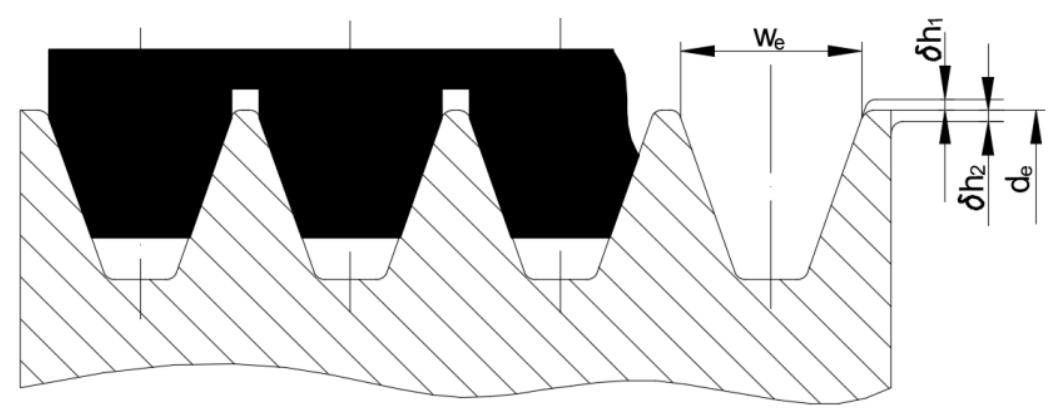

Fig. 6. Depth variations of the groove in comparison to the effective diameter

Values $\delta_{\mathrm{h}}$ and $\delta_{\mathrm{h}}$ were chosen in such a way so that the external pulley diameter did not adjoined the connecting tape (it could cause the separation of the connecting tape from the belts) at the same time ensuring such a depth of the groove that guarantees good power transmission.

\section{The measurements of geometrical features of the pulleys}

The measurement procedure of the parts with the application of noncontact optical system was presented in details in articles [15-17].

The research object was a V-belt pulley Poly-V with graduated scale $3.56 \mathrm{~mm}$ marked in catalogues by pulley producers as ,,$K^{\prime}$ and with external diameter of $50 \mathrm{~mm}$. Two pulleys were analyzed. First one was a brand new pulley and the second one was taken from a car with a mileage of $125,000 \mathrm{~km}$. The analysis of accuracy of mapping the geometrical shape of manufactured cogbelt pulleys was conducted with the use of noncontact optical system based on coordinate optical scanner GOM Atos Compact Scan $5 \mathrm{M}$ (Fig. 7). In order to conduct the measurement the measurement area SO 125 was used with the measurement range of $25 \times 90 \times 90 \mathrm{~mm}$. The scanning accuracy for this measurement area is at the level of $0.01 \mathrm{~mm}$.

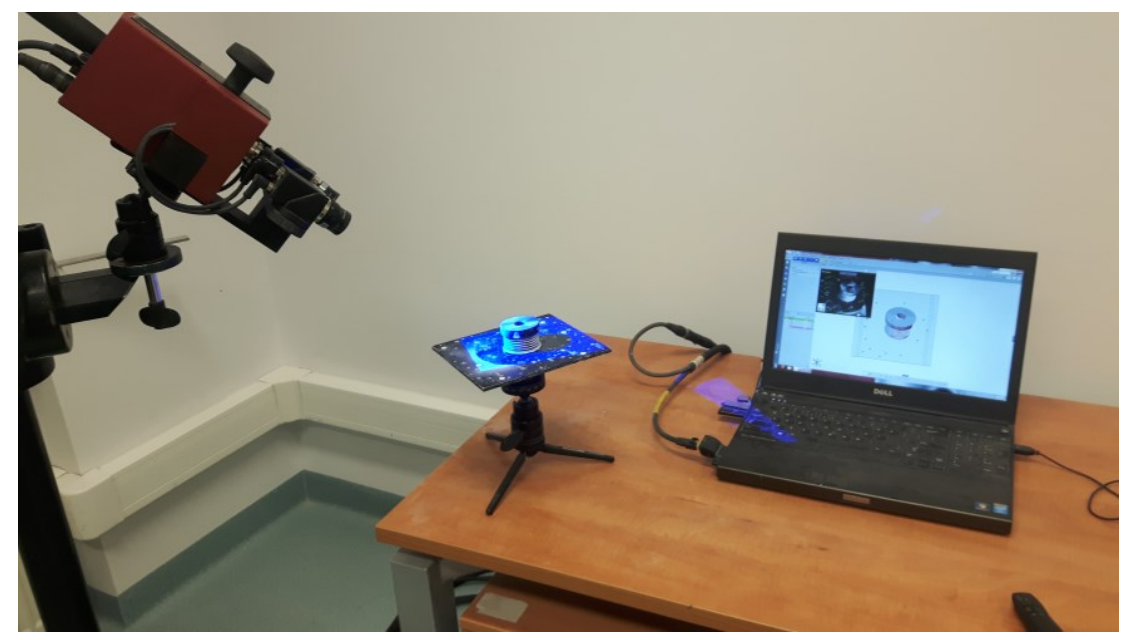

Fig. 7. The measurement of geometric characteristic of cogbelt pulleys with the use of ATOS II system 
Before scanning the measured pulley was covered with a thin layer of chalk to obtain a matt surface CAD model was created in Autodesk Inventor Professional V15 system on the basis of dimensions available in the catalogues provided by the pulley producers in accordance with ISO 9982 standards (Table 1).

Table 1. Dimensions of multi-groove pulleys

\begin{tabular}{|l|c|c|c|c|c|}
\hline Profile & $J$ & $K$ & $L$ & $M$ \\
\hline$a\left[^{\circ}\right]$ & $40 \pm 0.5$ & $40 \pm 0.5$ & $40 \pm 0.5$ & $40 \pm 0.5$ \\
\hline$p[\mathrm{~mm}]$ & $2.34 \pm 0.3$ & $3.56 \pm 0.5$ & $4.70 \pm 0.5$ & $9.4 \pm 0.8$ \\
\hline $\begin{array}{l}\text { tolerance } \\
\Sigma p[\mathrm{~mm}]\end{array}$ & \pm 0.3 & \pm 0.3 & \pm 0.3 & \pm 0.3 \\
\hline$r_{\text {tmin }}[\mathrm{mm}]$ & 0.20 & 0.25 & 0.40 & 0.75 \\
\hline$r_{b \min }[\mathrm{mm}]$ & 0.40 & 0.50 & 0.40 & 0.75 \\
\hline$s_{\min }[\mathrm{mm}]$ & 1.8 & 2.5 & 3.3 & 6.4 &
\end{tabular}

The model of pulley after scanning was put on CAD model with the use of Best fit method. The measurement analysis was made with the use of software GOM Inspect Professional V7 SR2. The exemplary measurement results are shown in Figures 8-10.

The inaccuracy on the edges of the pulley (dark blue colour) is a result of an inaccurate deflection of the pulley edge in reference to CAD model. The same refers to the inaccuracies of holes lowering the weight of pulley. These inaccuracies are irrelevant for the proper functioning of the transmission.
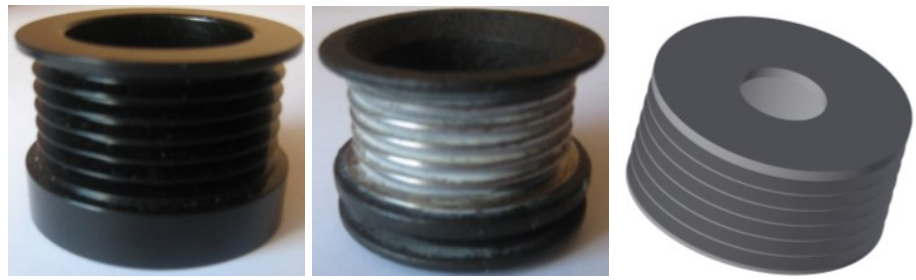

Fig. 8. A new pulley and a pulley with an exploitation time of about $250,000 \mathrm{~km}$

The assessment of geometrical features of pulleys was made in four reference planes placed at 90, 180, 270, 360 degrees accordingly.

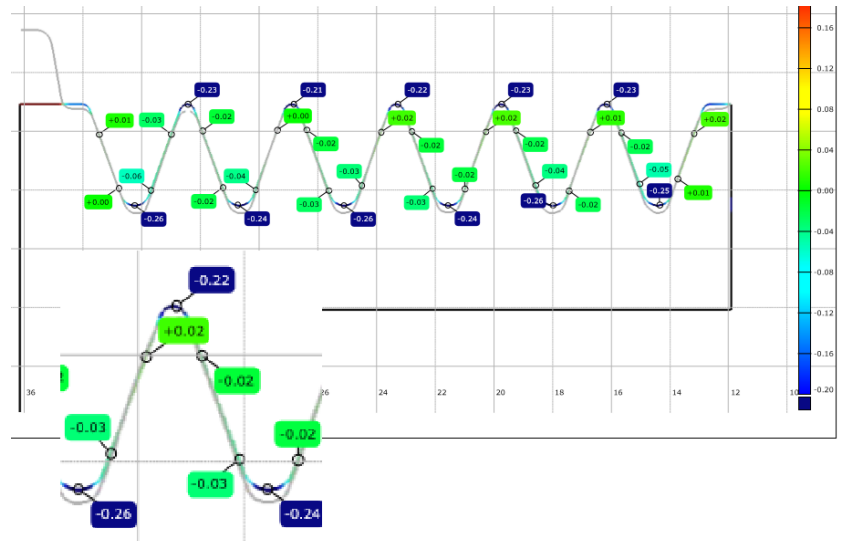

Fig. 9. Dimensional differences between CAD model and a new pulley 
This article shows exemplary value differences between a perfect pulley created in CAD system and a new pulley (Fig. 9) and a worn one withdrawn from use (Fig. 10). The distance unit applied in these figures is $\mathrm{mm}$.

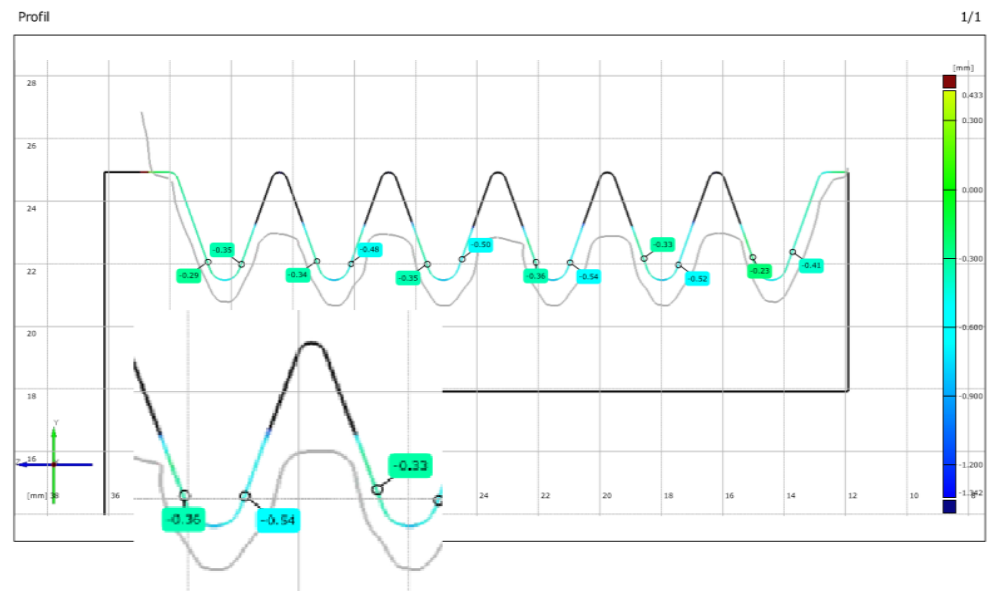

Fig. 10. Dimensional differences between CAD model and a worn pulley

The visible differences reaching $0.54 \mathrm{~mm}$ indicate that there was a severe wear of the pulleys which is a ground for their replacement.

The cause of such a high wear of pulleys may be:

- unproper assemply by a mechanic in a workshop,

- material failure occurring in the product,

- drive exploitation time (with proper exploitation it should hold about 120,000 km).

\section{Conclusions and suggestions for designers}

The issues connected with the assessment of the geometrical features of belt and multigroove pulleys were presented in this article. A fast and reliable measurement method of such pulleys with the use of optical scanner was indicated. Also the hints and recommendations for the designers and users of belt transmissions were listed. On the basis of the carried out research it can be concluded that in order to ensure a proper exploitation time of belt and multi-groove pulleys it is necessary to:

- apply a proper tension of the belt,

- using only the pulleys that were manufactured in accordance with the standards, chosen from catalogues of recognized producers,

- using in a transmission belts from one manufacturer ( with the same dimension tolerance),

- periodic control of pulleys and grooves cleanness,

- control of acceptable nonaxial and axial and plane of the transmission,

- control of proper assembly of the belt tensioner.

\section{References}

1. F.M. Feldhaus, Maszyny $w$ dziejach ludzkości. (PWN 1958)

2. D. Wojtkowiak, K. Talaśka, I. Malujda, G. Domek, Analysis of the influence of the cutting edge geometry on parameters of the perforation process for conveyor and transmission belts. MATEC Web of Conferences, Vol. 157, art. no 010222018, (2018) 
3. M. Kujawski, P. Krawiec, Analysis of Generation Capabilities of Noncircular Cog belt Pulleys on the Example of a Gear with an Elliptical Pitch Line, Journal of Manufacturing Science and Engineering-Transactions of the ASME 133(5), Article Number: 051006 (2011)

4. J. Flizikowski, M. Macko, Method of estimation of efficiency of quasi-cutting of recycled opto-telecommunication pipes, Polymers, tom XLVI, s. 53-59 (2001)

5. K. Wałęsa, I. Malujda, K. Talaśka, Butt welding of round drive belts. Acta Mechanica et Automatica 12 (2), 115-26 (2018)

6. S. Medvecká-Beňová, Meshing Condition and Kinematic Properties of non-circular GearActa. Mechanica Slovaca 20 (2), 16-21 (2016)

7. P. Krawiec, A. Marlewski, Profile design of noncircular belt pulleys. Journal of Theoretical and Applied Mechanics, 54 (2), 561-570 (2016)

8. F. Zheng, X. Guo, M. Zhang Non-uniform flank rolling measurement for shaped noncircular gears, Measurement 207-215 116 (2018)

9. G. Domek, A. Kołodziej, M. Dudziak, T. Woźniak Identification of the quality of timing belt pulleys, Procedia Engineering, Vol. 177, 275-280 (2017)

10. S. Wojciechowski, Machined surface roughness including cutter displacements in milling of hardened steel, Metrology and Measurement Systems Vol. XVIII (3), 429 440 (2011)

11. M. Vaško, M. Blatnický, P. Kopas, M. Sága, Badanie trwałości zmęczeniowej spoin spawanych stopu aluminium AlMgSi07.F25 pod cyklicznym obciązeniem skrętnoskrętnym. Metalurgija 56 (1-2), 94-98 (2017)

12. P. Kopas, M. Blatnický, M. Sága, M. Vaško, Identyfikacja właściwości mechanicznych złaczy spawanych stopu aluminium AlMgSi07.F25. Metalurgija 56 (1-2), 99-102 (2017)

13. M. Sága, P. Kopas, M. Uhríčik, Modelowanie i analiza doświadczalna uszkodzeń zmęczeniowych stopu aluminium w przypadku zginania - obciązenie skrętne. Procedia Engineering 48, 599-606 (2012)

14. P. Krawiec, Numerical Analysis of Geometrical Characteristics of Machine Elements Obtained Through CMM Scanning, Progress in Industrial Mathematics, SpringerVerlag, Berlin-Heidelberg, 925-930 (2010)

15. P. Krawiec, G. Domek, Ł. Warguła, K. Waluś, J. Adamiec The application of the optical system ATOS II for rapid prototyping methods of nonclassical models of cogbelt pulleys. MATEC Web of Conferences, Vol. 157, art. no 01010 (2018)

16. P. Krawiec, M. Grzelka, J. Kroczak, G. Domek, A. Kołodziej, A proposal of measurement methodology and assessment of manufacturing methods of nontypical cog belt pulleys, Measurement, 132, 182-190 (2019)

17. R. Majchrowski, M. Grzelka, M. Wieczorowski, Ł. Sadowski, B. Gapiński, Large area concrete surface topography measurements using optical 3D scanner, Metrology and Measurement Systems., Vol. XXII, (4), 565-576 (2015) 